\title{
The Design of VLC-PLC System for Substation Inspection
}

\author{
De-Dong Sun1, Tao-Rong Gong,2, , Rui Liư ${ }^{2,3}$, Jian Song', Guan-Hong Wang5 \\ ${ }^{1}$ State Grid Information \& Telecommunication Group Co. Ltd., Beijing, China \\ ${ }^{2}$ State Grid Key Laboratory of Power Industrial Chip Design and Analysis Technology, Beijing Smart-Chip Microelectronics \\ Technology Co., Ltd. Beijing, China \\ ${ }^{3}$ Beijing Engineering Research Center of High-reliability IC with Power Industrial Grade, Beijing Smart-Chip Microelectronics \\ Technology Co., Ltd. Beijing, China \\ ${ }^{4}$ Tsinghua University, Beijing, China \\ ${ }^{5}$ China Electric Power Research Institute, Beijing, China \\ Email: gongtr@163.com
}

How to cite this paper: Sun, D.-D., Gong, T.-R., Liu, R., Song, J. and Wang, G.-H. (2017) The Design of VLC-PLC System for Substation Inspection. Energy and Power Engineering, 9, 581-588. https://doi.org/10.4236/epe.2017.94B064

Received: March 9, 2017 Accepted: March 30, 2017 Published: April 6, 2017

\begin{abstract}
A kind of integrated network architecture visible light communication (VLC) and power line communication (PLC) is put forward. This architecture is low cost and easy to implement which overcomes the shortcoming of the traditional network architecture. Furthermore, the VLC-PLC integration technology is applied to typical power grid business scene, which is substation intelligent inspection. The business process of master station platform is analyzed. During the intelligent inspection, the VLC-PLC system provides voice communication for on-site inspection personnel and management personnel, and position service. The system can ensure the safety and security of power production.
\end{abstract}

\section{Keywords}

VLC, PLC, Intelligent Inspection, Voice Communication, Location Service

\section{Introduction}

Visible light communication (VLC) is a technical means to realize wireless communication based on LED lighting. With the traditional radio communication and other wireless optical communication technology, VLC does not occupy the radio spectrum resources [1]. It is ubiquitous, high transmission rate, no electromagnetic radiation, no electromagnetic interference, and so on. It is believed that when the wireless spectrum resource is limited, deep fading or sensitive electromagnetic, the VLC is with prospects and advantages [2] [3] [4]. So it 
has been widely concerned by academic and industrial circles. Power line communication (PLC) makes power transmission and communication signal transmission on a cable to complete, and make the signal can be transmitted directly to the LED through the power line. Therefore, the combination of PLC and VLC has a natural advantage, overcoming the shortcomings of traditional wired networks and radio frequency networks [5] [6] [7]. On the other hand, there are many radio signals and other sensitive electromagnetic deep fading scenarios in power grid business environment, such as smart substation and power production. The traditional communication radio network is difficult to apply, but based on hybrid VLC-PLC network can be very good for these occasions. In order to overcome the drawbacks of traditional integrated VLC-PLC [8], network architecture is proposed with VLC-PLC deep integration. Taking typical scenes in power grid services as an example, the analysis of the current difficult to meet the needs of the business can be used by this system.

\section{VLC-PLC Network Architecture}

At present, the research of VLC and PLC integrated network architecture is very limited. As shown in Figure 1, as traditional network architecture of VLC and PLC collaborative work, PLC signal needed to be demodulating, decoding, re-encoding which drives LED lamp before accessing each LED. The disadvantage of this architecture is to scale the existing lighting network, and the reconstruction project is complex. Also the cost is high. Mainly there are following problems.

1) Due to the overlap of adjacent LED light irradiation area, there are serious adjacent area interference;

2) Due to the small coverage area of each LED lamp, the user will face frequent switching in different LED coverage area, which leads to the instability of signal reception;

3) Infrared or radio frequency technology as a low speed uplink is asymmetry with VLC high speed downlink [9].

In order to solve these problems, a kind of broadband access network is studied based on VLC-PLC depth fusion, as shown in Figure 2. Multiple LED



Figure 1. The collaborative work network architecture of traditional VLC and PLC. 




Figure 2. The network architecture VLC-PLC depth integrated communication.

lamps are connected to the same power line, which is connected with the PLC modem for the information exchange with the background Ethernet. Multiple LED lamps transmit to the user with VLC independent data signal, and the user receives the signal through the handheld terminal, which supports VLC uplink transmission. The detector of LED lamp demodulates the uplink signal, and then transmits to the PLC backbone network. This scheme encodes and modulates for the VLC-PLC joint channel uniformly, which avoid the problems of traditional VLC-PLC.

This hybrid VLC-PLC system collaboratively works, and doesn't upgrade to existing lighting network. There are not regional interference and handover problems because of the user in the LED mobile regional. In addition, the VLC-PLC communication network can have uniform coverage due to the lighting illumination satisfying uniform coverage characteristics. The means that this architecture is lower cost and easier to achieve than that of traditional architecture.

\section{The Application of VLC-PLC for Substation Inspection}

\subsection{Substation Inspection}

Substation realizes voltage levels alternation. It is the key energy node of a city. So the safe and stable operation of substation is related to the social and economic development and social stability. In order to ensure the normal operation of substation, the regular manual inspection of substation is needed. During substation inspection activities, "in place detection" is an important content of the assessment for inspection personnel. There are following problems.

1) How to ensure that the inspection personnel reach each subject position in the inspection process.

2) How to ensure that the inspection personnel and operating equipment maintain a safe distance to other facilities in the station.

Therefore, in order to ensure the safety and normal work of patrol personnel, the real-time position of the inspector is demanded.

At the same time, there is a strong demand for the network information ser- 
vice in the substation inspection, which can provide the patrol officers with the functions of reporting, remote guidance, real-time information recording, archiving, and so on. On the other hand, patrol officers often need to voice calls with the dispatcher when they found the problem in the work. They need to return to the office to call the internal telephone, and then back to the scene. However, due to the factors such as electromagnetic interference and security, it is difficult to meet the above requirements based on traditional radio frequency communication.

\subsection{Intelligent Patrol Network Structure}

The VLC-PLC system can be used to solve the problems of substation inspection. The use of LED lights in the substation will not produce radio waves, not interfere with the substation equipment. LED is as a communication node, so inspection personnel can always maintain network connectivity with backstage operation system in the inspection, gain information services, and communicate securely. At the same time, accurate positioning for inspection personnel and equipment operation is obtained.

Using VLC and PLC fusion technology set up the optical communication local area network in the substation, as shown in Figure 3, which is network schematic diagram for the intelligent substation inspection. The work data of service system is transmitted to the LED lighting at different positions in substation through the network. Then the data is modulated by the transceiver at the source. The modulated optical signal is loaded to the LED to transmit. The on-site inspection personnel can receive VLC signal through the transceiver at the user terminal, which realizes the data communication service and positioning service. At the same time, the user terminal transceiver transmits location information and communication data through uplink VLC signal, realizing real-time monitoring and interactive information with backstage management operator. On the one hand the system can confirm that the inspection personnel

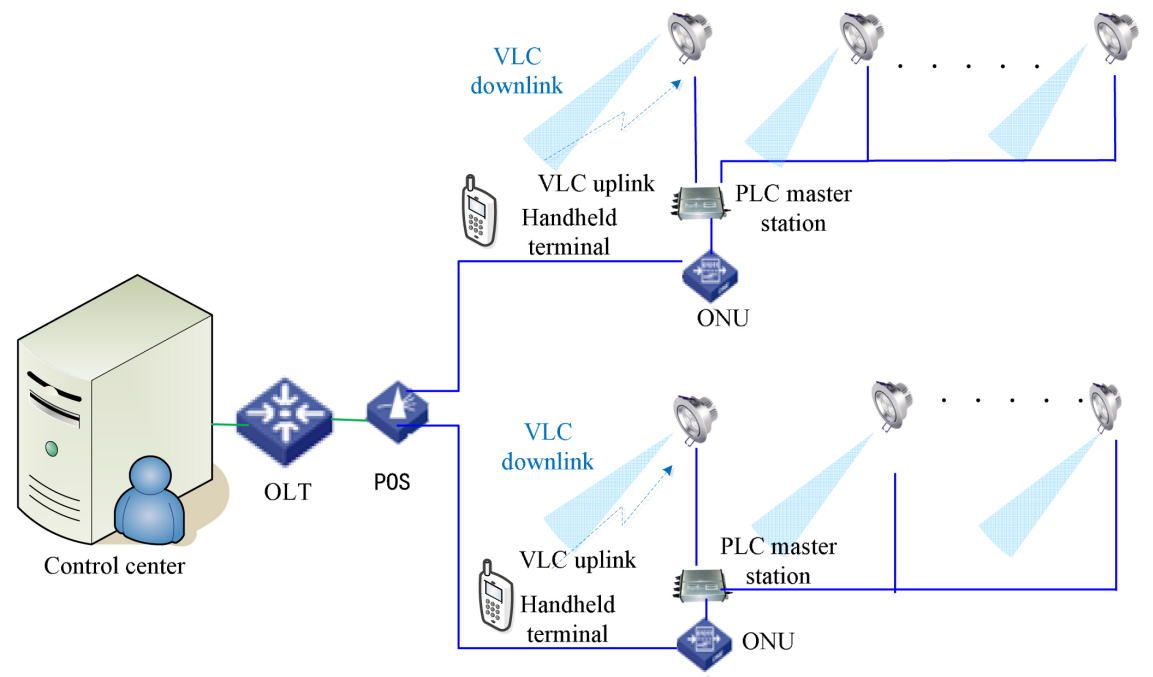

Figure 3. The sketch of intelligent network structure of substation or cable tunnel. 
arrive at the scene and inspect according to predetermined route, on the other hand secure and convenient wireless information service is provided for the inspection personnel. There for the inspection personnel can acquire the information, report the field data, and upload examined numerical value, and so on through the handheld whenever and wherever possible. In addition, the use of VLC positioning confirm the exact location of the patrol personnel and their equipment in space, make timely warning to their illegal operation, and ensure their life safety in the whole process of inspection.

\subsection{Business Process and Function of the System}

The hybrid VLC-PLC system mainly includes the master server, PLC mater station, LED light transceiver which is including PLC base station, handheld terminal. There is only one master node in each PLC transmission network, and others are the base station node. PLC base station is connected to the base station node, and PLC master station connected to the master node. Only the base station node and the master node can communicate each other, the base station node and the base station node can't communicate each other. The PLC master node has the function of broadcast and unicast, and the PLC base station node only has the function of unicast. The diagram of hybrid VLC-PLC system business is shown in Figure 3, the main processes are as follows.

1) The master station transmits the information source through the power line to the LED light source terminal transceiver, which is converted into optical signal and sent to the handheld terminal.

2) The use of LED lighting and PLC network, not only can send the data of the master station to handheld terminal, and also can receive, and process VLC data sent by the handheld terminal. At the same time, the master station can share upload data of a terminal user to other terminal users.

The function of the system is as follows mainly:

1) Positioning and track record: the system can locate the personnel with handheld device and their real-time and historical trajectory.

2) The main station sound broadcast and the equipment calls the mutual transmission: the master station may broadcast to all equipment; the equipment may also carry on the conversation through the system.

3) Sound harmonic and instant storage: many people speaking of the voice playback and voice storage problems are solved by real-time mixing technology.

4) Equipment health status monitoring: it is monitored that and showed on the interface whether the LED device is online or whether it is in the working state.

\subsection{The Design of Master Platform}

The diagram of master station business structure is shown in Figure $\mathbf{4}$ for the hybrid VLC-PLC system, including the application layer, the control layer and the support layer. The function of each layer is as follows.

1) The application layer provide users with communication services, location 


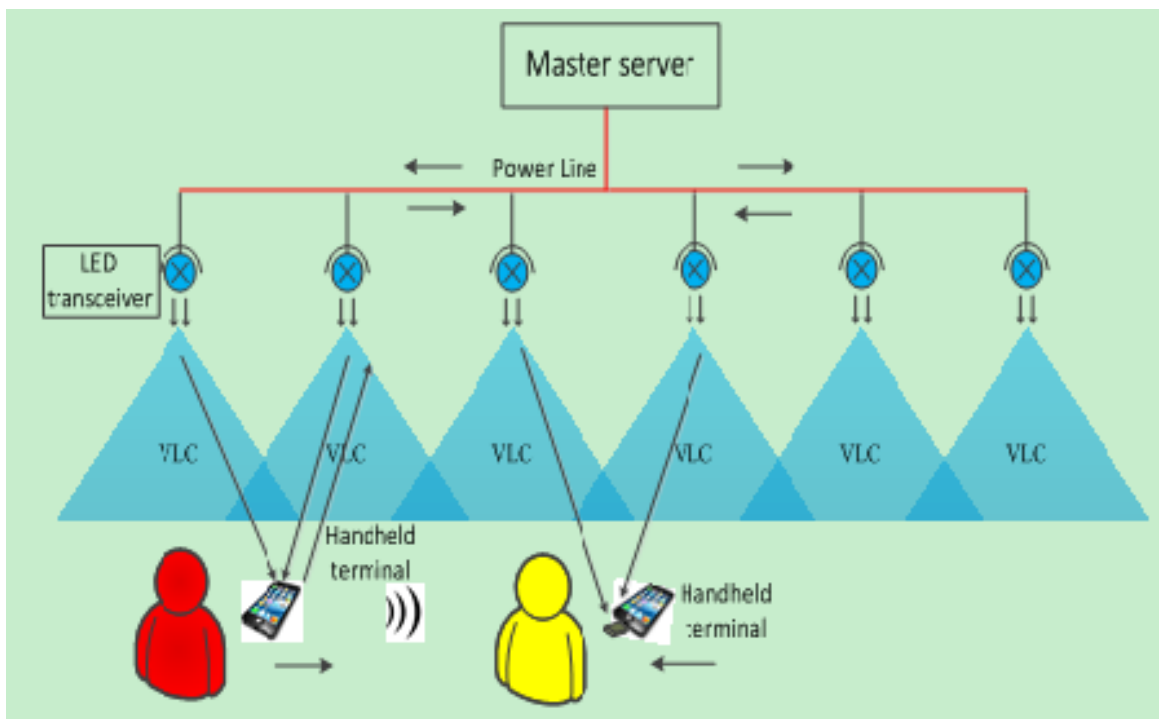

Figure 4. The diagram of hybrid VLC-PLC system service.

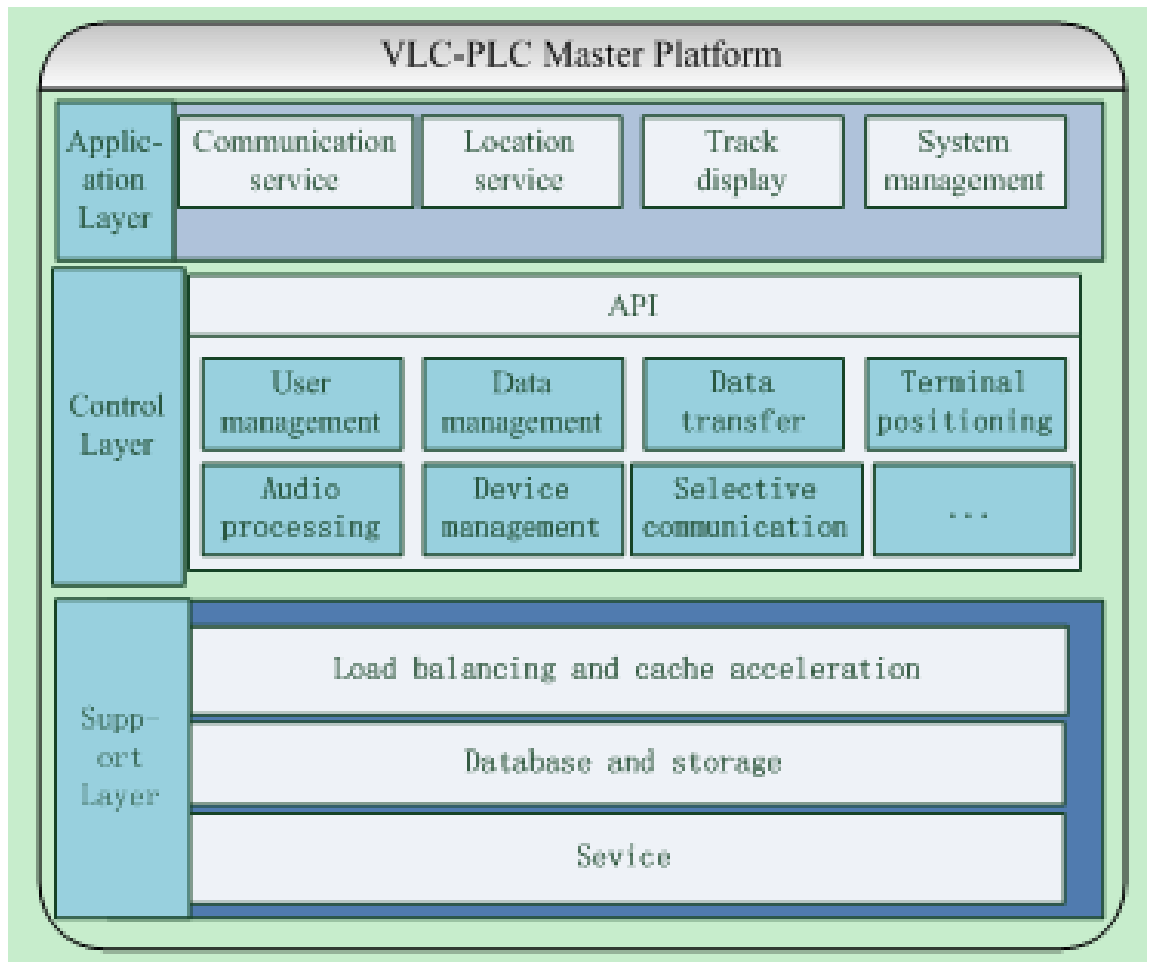

Figure 5. The diagram of master station business structure of hybrid VLC-PLC system.

services, track statistics display services and system management services

2) On one hand the control layer provide the application layer call interface with various functions, on the other hand, the management users and data resources of system. The control layer provides data transfer, terminal positioning, audio processing, selective communication and other functions. Also it manage systems user, allowing access system equipment and recording all data.

3) The support layer mainly completes load balancing, cache acceleration, data storage and so on. 
Load balancing is built on the existing network structure. It provides a cheap, effective and transparent method of expansion of network equipment and server bandwidth, increasing throughput, enhancing network data processing ability, increasing network flexibility and availability.

Cache acceleration is a strategy of using server memory fully, which can speed up the whole system running smoothly. Combined with VLC master system, it is demonstrated mainly that using buffer queue and multi thread parallel processing technology improve performance of the system when the system receive terminal data, encode, assemble, transmit data, and parallel process multiplex data.

The relational database storage system is a kind of easy to use, stable and reliable, retractable on-line database service. It is with multiple safety protection measures and perfect performance monitoring system, and provide professional database backup, recovery and optimization scheme.

\section{Conclusion}

A VLC-PLC deep integration network architecture and communication system is presented, which can be used for wireless RF signal fading deeply and electromagnetic sensitive scenes. Furthermore the system is applied to the substation intelligent inspection system in power grid service. The network structure, business process and the mater station of the system are analyzed, which can realize two-way voice communication and positioning service. Next step the system will be verified and tested in a power supply, which will provide experience for the application of hybrid VLC-PLC system in the power grid business.

\section{Acknowledgements}

The work is supported by Science and Technology project of State Grid Corporation of China (Grant No. SGHAZZ00FCJS1500238).

\section{References}

[1] Chi N. (2015) Key Devices and Applications of LED Visible Light Communication. Post and Telecom Press, Beijing.

[2] Yang, L.W., Hou,C. andChen, Q. (2014) Research on Integrated System of Visible LightCommunication with PLC. Telecommunications Network Technology,2, 58-61.http://en.cnki.com.cn/Article_en/CJFDTotal-DXWJ201402018.htm

[3] Pujapanda, K.P. (2013) LiFi Integrated to Power-lines for Smart Illumination Cumcommunication.International Conference on Communication Systems and Network Technologies, IEEE, India,Gwalior, 4-6, April 2013， 875-878.

https://doi.org/10.1109/CSNT.2013.189

[4] Rezaie, H., Hashemiyan, Z., AbuSahmah, M., et al.(2011) Application of DFE on integrated system of VFSO and Broad Band Power Line Communication.17th Asia-Pacific Conference on Communications, IEEE, Sabah, Malaysia, 9-11 September 2011, 273-277.

[5] Komine, T.,Haruyama, S. and M. Nakagawa. (2006)Performance Evaluation of Narrowband OFDM on Integrated System of Power Line Communication and Visible Light Wireless Communication.1 st International Symposium on Wireless Perva- 
sive Computing,IEEE, Japan, 17-19,February, 2006, 10-16.

[6] Alavi, S.E., Supa'at, A.S.M.,Idrus,S. M. (2010) Fuzzy Equalized Integrated System of Visible Free Space Optic (VFSO) and BPLC.5th International Conference on Broadband and Biomedical Communications, IEEE, Malaga, Spain, 6-8 December2010, 1-6.

[7] Alavi, S.E., Rezaie,H., Supa'at, ASM.(2010) Application of OFDM on Integrated System of Visible Free Space Optic with PLC. Asia-Pacific Conference on Applied Electromagnetics, IEEE, PortDickson, Malaysia, 9-11 November 2010, 1-5.

[8] Komine, T. and Nakagawa,M. (2003) Integrated System Of White Led Visible Light Communication and Power-Line Communication. IEEE Trans. Consum. Electron., 71-79. http://10.1109/TCE.2003.1205458

[9] Song,J., Ding, W., Yang,F.et al. (2015) An Indoor Broadband Broadcasting System Based on PLC and VLC.IEEE Transactions on Broadcasting, 2,299-308.http://10.1109/TBC.2015.2400825

\section{Scientific Research Publishing}

Submit or recommend next manuscript to SCIRP and we will provide best service for you:

Accepting pre-submission inquiries through Email, Facebook, LinkedIn, Twitter, etc. A wide selection of journals (inclusive of 9 subjects, more than 200 journals)

Providing 24-hour high-quality service

User-friendly online submission system

Fair and swift peer-review system

Efficient typesetting and proofreading procedure

Display of the result of downloads and visits, as well as the number of cited articles

Maximum dissemination of your research work

Submit your manuscript at: http://papersubmission.scirp.org/

Or contact epe@scirp.org 